\title{
Diabetes Mellitus Diagnosis Expert System with Web-Based Forward Chaining
}

\author{
Rusdiansyah $^{1}$ \\ Bina Sarana Informatika University \\ Street. Kamal Raya No.18, Ring Road Barat, West \\ Jakarta City, Special Capital Region of Jakarta \\ Rusdiansyah.rds@bsi.ac.id
}

\author{
Santoso Setiawan ${ }^{2}$ \\ Bina Sarana Informatika University \\ Street. Kamal Raya No.18, Ring Road Barat, West \\ Jakarta City, Special Capital Region of Jakarta \\ Santoso.sts@bsi.ac.id
}

\author{
Mohammad Badrul ${ }^{3}$ \\ STMIK Nusa Mandiri \\ Street. Kramat Raya No.18, Kwitang, Senen, Central Jakarta City, \\ Jakarta Special Capital Region \\ Mohammad.mbl@nusamandiri.ac.id
}

\begin{abstract}
Diabetes Mellitus Diagnosis Expert System with Web-Based Forward Chaining Method. An expert system is one branch of artificial intelligence technology that combines the knowledge of an expert with tracing data to solve problems that are normally carried out by an expert. The development of information technology now makes it possible to access information from anywhere and anytime. So the role of information technology is increasingly useful to be able to develop in various fields including in the health sector. One of them is the system used to diagnose diabetes mellitus. Diabetes Mellitus is one of the most common diseases in the world. The inability of the pancreas to produce insulin normally becomes one of the reasons a person has this disease. In this research, the method used is Forward Chaining which sorts all data obtained before getting the final conclusion. Based on the testing of user requirements (software validation testing), the percentage of fulfillment of needs is $100 \%$, while the test results are $90 \%$ system accuracy. The results of this test indicate that the system of diagnosing Diabetes Mellitus can be used to help ordinary people in diagnosing Diabetes Mellitus.
\end{abstract}

Keywords_-Diabetes Mellitus, Expert System, Forward Chaining.

\section{INTRODUCTION}

The development of information technology has undergone rapid and dynamic changes (Sri Maharsi, 2000). This is influenced by the needs of individuals who want a better change from existing information technology. So the role of information technology is increasingly useful to be able to develop in various fields including in the health.

Diabetes Mellitus is a disease characterized by high blood sugar levels caused by interference with insulin secretion or insulin disruption or both (Prameswari \& Widjanarko, 2014). Insulin itself is a hormone released by the pancreas that is responsible for maintaining blood sugar levels (Wardan, 2014). The body of patients with Diabetes Mellitus cannot produce or cannot respond to the hormone insulin produced by the pancreatic organs, so that blood sugar levels increase and can cause short-term and long-term complications in these patients.

There are several types of Diabetes Mellitus namely Diabetes Mellitus Type I, Type II Diabetes Mellitus, Gestational Type Diabetes Mellitus and Diabetes Mellitus Other Types (Wardan, 2014). The most common type of diabetes mellitus is Type II Diabetes Mellitus which is caused by an increase in blood sugar or impaired insulin function. Insufficient knowledge about the symptoms and how to deal with 
diabetes mellitus is one of the causes of the increase in people affected by the disease.

In this case the use of expert systems is very helpful in the process of making a diagnosis of 1 . infectious diseases where as a substitute for an expert. By using forward logic and backward chaining logic, it is hoped that an expert system based on information technology can be built to assist in making a diagnosis of tropical infectious. Tropical Infection Diagnosis Expert System Using Forward And Backward Chaining(Satyareni, Sistem, \& Fakultas, 2011).

\section{LITERATURE REVIEW}

\subsection{Basic Concepts of the Program}

Programming language is a means of communication that connects human beings to computers (Afrina, Ibrahim, Sistem, Fasilkom, \& Sriwijaya, 2015). The process of computer programming is not just writing an instruction that must be done by a computer, but also aims to solve a problem and make work easy or other things that are desired by the user (Rusdiansyah, 2018).

There are 3 important factors in programming languages:

1. Syntax is the rule for writing the language (grammar)

2. Semantic is the intention contained in the statement.

3. The Logic Truth is related to whether or not the order of statements is true.

One stage of the construction of a program is to translate or encode detailed designs that have been made into a computer program that is ready to use. Translating means that we do program writing using a programming language that we master.

\subsection{Web Application}

The web is short for websites, namely an information presentation service that uses the concept of hyperlinks or links one page to another. Information presented by the web uses multimedia concepts from multi-text, images, animation, sound (audio), and film (video)(Rusdiansyah, 2018). While the internet is a source of information and computer resources that reaches the entire world. The internet comes from the word interconnection networking, inter stands for the word international, connection means a relationship, while networking is a network, so that the internet can be defined as a network consisting of various types of computers around the world that communicate with each other based on a protocol called TCP / IP (Transmission Control Protocol / Internet Protocol).

\subsection{PHP}

PHP stands for (Personal Home Page) Hypertext Processor. PHP is a web programming language or scripting language that is designed to create webbased applications. is a server-side script language that is open source. PHP language integrates with HTML scripts that are fully run on the (Canggih Aji Pamungkas, 2015).

PHP is an Open Source product that can be used for free without having to pay to use it. The installer file can be downloaded for free at the address http://www.php.net.

\subsection{Database}

Understanding database systems are computerized systems that are maintaining data that has been processed or confirmed and made information available when needed (Susanto, 2011). In essence the database is the media for storing data so that it can be accessed easily and quickly. This book uses a relational database that is implemented with tables that have mutual relations.

\subsection{System Development Life Cycle (SDLC)}

In the system development phase the writer uses the Framework System Development Life Cycle (SDLC) (Kermite et al., 2012) with a waterfall approach consisting of several stages of activity flow that runs one direction from the beginning to the end of the system development project, there are certain stages that must be achieved in the same direction after the other stages, in a certain order, such as a staircase or multilevel waterfall. Several different stages in this method. Several different stages in this method, generally ranging from feasibility studies, requirements, architecture, design, development, testing, deployment and operation.

\subsection{Unified Modeling Language (UML)}

UML (Unified Modeling Language) is a modeling language for systems or software that is object oriented paradigm (Alfarisyi \& Amila, 2014). That is a rather simple definition. In fact, UML is a different thing for several different people. This comes from both its own history and from a different perspective that people have about what makes an effective software engineering process. Use Case Diagram is a graphical presentation that can provide a list of use cases that occur in an application. Activity Diagram is a workflow diagram that describes 
various user or system activities, people who do each activity, and sequential flows and those activities. Activity diagram has a role like flowchart, but the difference with flowcharts is that activity diagrams can support parallel behavior while flowcharts cannot. Component diagrams basically show the structure and relationships between software components including dependencies between these components Deployment Diagrams describe the details of how components are formed and distributed in the system infrastructure.

\subsection{Entity Relationship Diagram (ERD)}

Entity Relationship Diagram is a diagram used to design relationships between tables in the database (Rusdiansyah, 2018).

\subsection{Forward chaining method}

An inference that connects a multiplication problem with solution called chain. A chain is sought or is bypassed or crossed from a problem to obtain the solution referred to as Forward Chaining. Another way of describing the forward chaining this is by reasoning from facts leading to the conclusion that there is from the facts. In the advanced rules of reasoning are tested one by one in a specific order. The sequence may be either a sequence of rules of incorporation into the base rules or also other sequence determined by the user. Each time a rule is tested, the expert system will evaluate whether conditions are true or false. If the condition is true, then the rule is kept then the next rule is tested. Conversely, if conditions are wrong, it is not stored and the next rule is tested. This process would be repeated until the entire base of the rules tested with a variety of conditions. Advanced reasoning work with problems that started with the recording of the initial information and the final settlement to be achieved, then the whole process will be done sequentially. Fig.1 shows the process forward chaining(Prambudi, Widodo, \& Widodo, 2018).

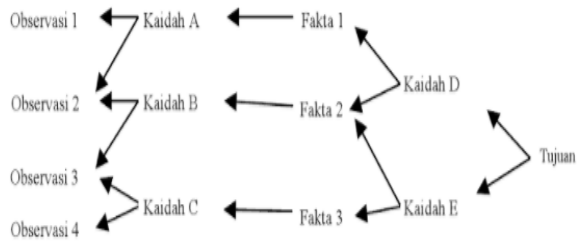

Fig.1, Forward chaining method

\section{III.PROPOSED METHOD}

In this study, the authors used 4 research methods, namely Observation, Interview, Library Study and Questionnaire. Observation is carried out by conducting direct observations of objects to obtain basic information on the object under study, namely Diabetes Mellitus. Whereas to obtain information about Diabetes Mellitus, the author conducted direct interviews with doctors (experts). The author also uses several literature such as scientific journals, book references, website articles and libraries. And also the author gave several questionnaires to respondents to find out the patient's response to this disease and program.

\section{RESULT AND DISCUSSION}

\subsection{Expert Interview Results}

From the results of interviews conducted with several experts, it is known that Diabetes Mellitus is a chronic disease caused by the inability of the pancreas to produce the hormone. Diabetes Mellitus is divided into 3 (three) types, namely: Type I Diabetes Mellitus, Type II Diabetes Mellitus and Gestational Diabetes (gestational diabetes). The common symptoms that are found in Diabetes Mellitus are Polyuria (lots of urination), Polydipsia (thirsty so it drinks a lot), Polyphagia (lots of eating due to constant hunger) and weight loss for no apparent reason.

\subsection{Knowledge Base}

Knowledge base is an important component of an expert system, the size of the ability of expert systems is usually determined by the capacity of the knowledge base, while decision-making machines are applications that help and guide expert system users in manipulating data and selecting appropriate knowledge to draw conclusions.

TABLE 3.1 EXPERT TABLES

\begin{tabular}{|c|c|c|c|}
\hline \multirow{2}{*}{ Rule } & DM tipe 1 & DM tipe 2 & DM tipe \\
& P01 & P02 & P03 \\
\hline G01 & & & v \\
\hline G02 & v & & \\
\hline G03 & v & v & v \\
\hline G04 & v & v & v \\
\hline
\end{tabular}




\begin{tabular}{|c|c|c|c|}
\hline G05 & v & v & v \\
\hline G06 & v & v & v \\
\hline G07 & v & v & v \\
\hline G08 & v & v & \\
\hline G09 & v & v & \\
\hline G10 & v & v & \\
\hline G11 & v & v & \\
\hline G12 & v & v & \\
\hline G13 & v & v & \\
\hline G14 & v & & \\
\hline G15 & v & & \\
\hline G16 & & & v \\
\hline G17 & & & \\
\hline G18 & & & \\
\hline
\end{tabular}

Information:

a. The first column explains the rule of various diseases (alternative from experts).

b. The first line shows the symptoms to the expert.

c. The cross sign shows what symptoms are used by the expert.

\subsubsection{Rules for Experts}

Rule 1 :

IF Genetics AND

Poliura AND

Polidipsia AND

Polifagia AND

Dehydration AND

Itching in the female genitals AND

Erectile dysfunction in men AND

Difficulty in breathing AND

Anxious, easily tired and tingling AND

Weight loss without obvious reasons AND

Blurred vision AND

Difficult healing of AND

Nausea and vomiting if there is no long-term intake of AND

Breath smells of acetone THEN

Diabetes Mellitus Type 1

Rule 2 :

IF Poliura AND

Polidipsia AND

Polifagia AND

Dehydration AND

Itching in female genitalia AND
Erectile dysfunction in AND men

Difficulty in breathing AND

Anxious, easily tired and tingling AND

Weight loss without obvious reasons AND

Blurred vision AND

Difficult wound healing THEN

Diabetes Mellitus Type 2

Rule 3 :

IF Pregnant AND

Poliura AND

Polidipsia AND

Polifagia AND

dehydration AND

Itching in female genitalia AND

Body weight is more than normal for the average pregnant person AND

swollen feet AND

A baby's ultrasound weighs more than $4 \mathrm{~kg}$ THEN Gestational Diabetes

\subsubsection{Expert Tree}

Decision tree is an answer to a system or a way that we develop to help find and make decisions for these problems and by taking into account the various factors that are within the scope of the problem.

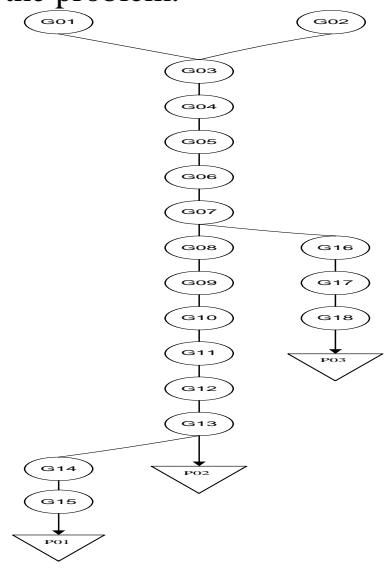

Fig.2, Expert Tree

\subsection{System Implementation}

\subsubsection{Use Case Diagram}

In Fig2. it explains the Design of Use Case Diagram of Expert System activities, Users access the Web according to the access. 


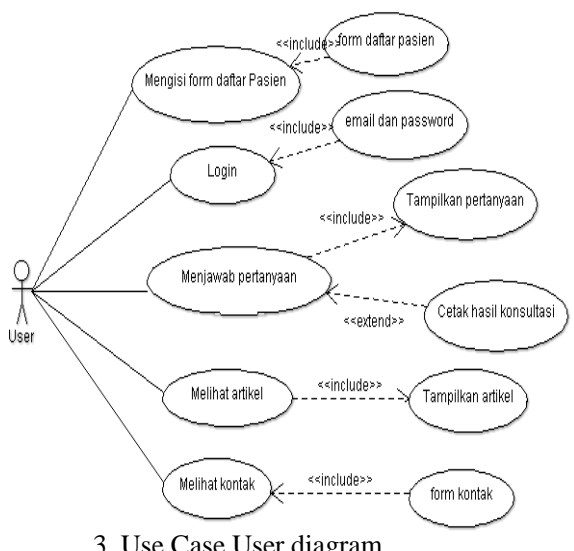

.3 , Use Case User diagram

\subsubsection{Entity Relationship Diagram}

Depiction of relationships between tables created and relations between tables in this expert system using ERD (Entity Relationship Diagram). Here is the picture:

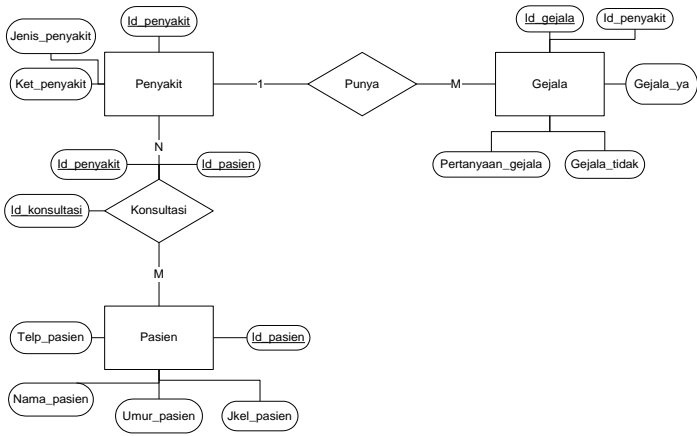

Fig.4, Entity Relation Expert System Diagram

\subsubsection{User Interface}

Users interact with expert system applications by accessing through the Website. With this Expert Application, users can consult directly and get information about the symptoms of Diabetes Mellitus.

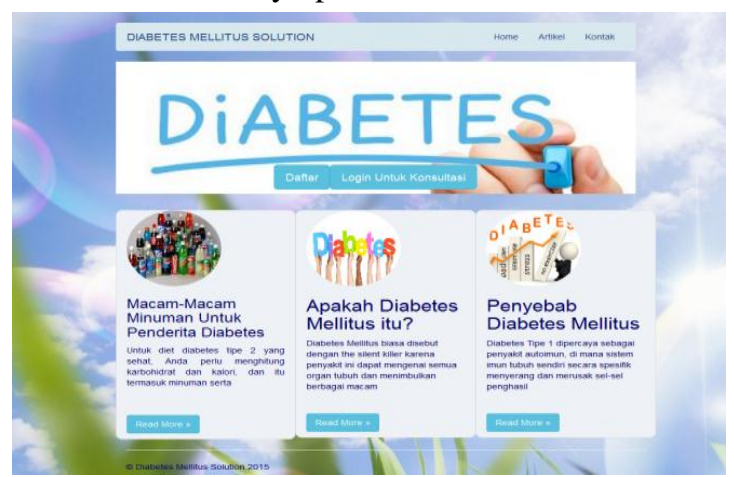

Fig.5, Main Expert System Display

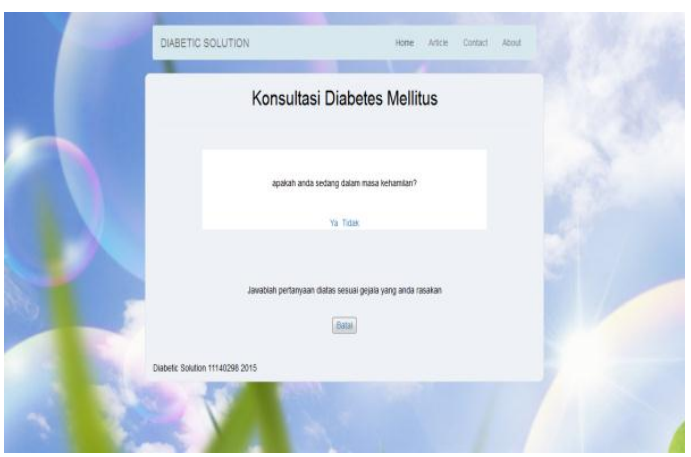

Fig.6, Consultation for Diabetes Mellitus

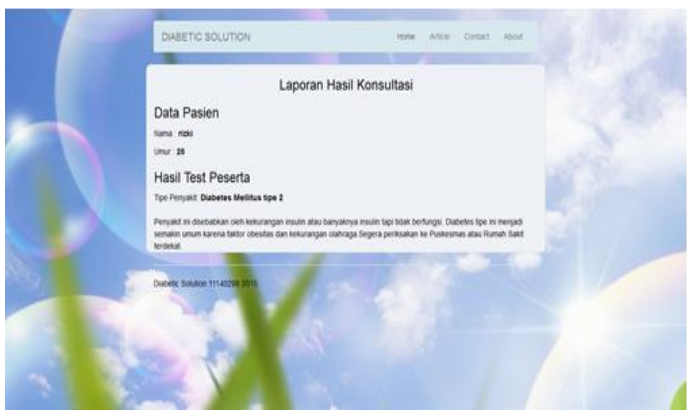

Fig.7, Consultation Results Report

\subsection{Testing}

What is meant by the white box method is a test case design method that uses procedural design control structures to obtain a test case. By using the white box testing method, the system engineering can carry out test cases that can :

1. Ensure that all independent paths in a module have been used at least oncetelah.

2. Using all logical decisions on the true and false sides.

3. Execute all loops on the boundary.

4. Operational application users.

Not all tests are carried out on the whole program as a whole, but in this case testing samples are carried out on certain stages that are carried out. For example, testing of one disease will be discussed, whose principle works the same as other diseases. Broadly speaking, the algorithm for consulting Diabetes Mellitus is as follows :

a. The user is asked to log in by entering an email and password.

b. If successful, the user can start the consultation. If not, return to the start page.

c. Users are asked to answer YES or NO questions about symptoms of the disease. 
d. If the user does not want to continue the consultation, the user can cancel the consultation and return to the start page.

e. If the user has finished answering the question, the results of the disease analysis will appear.

f. Users can continue to print the results or finish returning to the main menu.

Then it can be described with the flowgraph as follows:

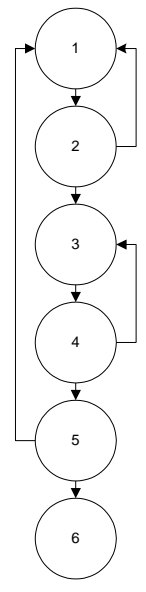

Fig 8, Flowgraph White Box

Cyclical Complexity (quantitative measurement of the logical complexity of a program)

from the flow chart can be obtained by calculation:

Where,

$$
\mathbf{V}(\mathbf{G})=\mathbf{E}-\mathbf{N}+\mathbf{2}
$$

$\mathrm{E}=$ the number of edges of the flow chart that is indicated by an arrow

$\mathrm{N}=$ the number of flow chart nodes that are indicated by a circle image.

so the complexity is cyclical

$$
V(G)=8-6+2=4
$$

Base sets generated from linear independent paths are the following paths:

$1-2-3-4-5-6$

$1-2-1-2-3-4-5-6$

$1-2-3-4-3-4-5-6$

$1-2-3-4-5-1-2-3-4-5-6$

When the application starts, it can be seen that one of the base sets generated is 1-2-3-4-5-6 and it appears that the node has been executed once. Based on these provisions in terms of the feasibility of the software this system has met the requirements.

\section{CONCLUSION AND SUGGESTION}

\subsection{Conclusion}

Based on the description of the problem, the purpose and objectives of the research and analysis of data processing that has been done, then it can be concluded that:

1. Based on the testing of user requirements (software validation testing), the percentage of fulfillment of needs is $100 \%$, while the test results are $90 \%$ system accuracy. The results of this test indicate that the system of diagnosing Diabetes Mellitus can be used to help ordinary people in diagnosing Diabetes Mellitus

2. This expert system is created by storing the expertise of Diabetes Mellitus experts who are expected to help experts themselves and the general public in diagnosing the possibility of someone affected by Diabetes Mellitus.

3. This system can provide convenience to the user just by answering questions that match the symptoms felt by the user. And the output, which is a diagnosis, can be used for assistance if the user checks the disease to the nearest health center or hospital.

\subsection{Suggestion}

Some things suggested for further development of this Expert System Application Program are as follows:

1. Some improvements are needed both from the appearance and content of this application, so that it can display expert knowledge that is more indepth in this expert system.

2. Develop an Android-based application so that more information about the type of diabetes mellitus is accepted by the general public.

\section{REFERENCES}

Afrina, M., Ibrahim, A., Sistem, J., Fasilkom, I., \& Sriwijaya, U. (2015). Development of SMS Gateway Information System in Improving Academic Communication Services Around the Faculty of Computer Science Unsri, 7(2), 852-864.

Alfarisyi, M. I., \& Amila, K. (2014). DESIGN OF WEB-BASED ITENAS ALUMNI SERVICE INFORMATION SYSTEMS, 02(01), 132143.

Canggih Aji Pamungkas. (2015). WEB-BASED ELEARNING CENTER DESIGN TO 
IMPROVE THE QUALITY AND

EFFECTIVENESS OF EFFECTIVE

LEARNING MEDIA. INFORMA Politeknik

Indonusa Surakarta, 1(2), 8-19.

Kermite, R. Y., Winarno, A., Rohmani, A., Informasi, S., Komputer, F. I., \& Nuswantoro, U. D. (2012). School Administration System Design with Web Based SMS Gateway Using Gammu at Semarang LPI Vocational School, (x), 1527.

Prambudi, D. A., Widodo, C. E., \& Widodo, A. P. (2018). Expert System Application of Forward Chaining and Certainty Factors Method for The Decision of Contraception Tools, 10009, 1-6.

Prameswari, O. M., \& Widjanarko, S. B. (2014). THE EFFECT OF PANDAN WANGI LEAF EXTRACT ON THE DECREASE OF BLOOD GLUCOSE LEVEL AND HISTOPATOLOGY OF DIABETES MELLITUS, 2(2), 16-27.

Rusdiansyah. (2018). EXPERT SYSTEM FOR DIAGNOSING THE DAMAGE OF MATIC MOTORCYCLE MACHINES WITH THE FORWARD CHAINING METHOD, 14(1), 35-42.

Satyareni, D. H., Sistem, J., \& Fakultas, I. (2011). TROPICAL INFECTION DISEASE DIAGNOSIS EXPERT SYSTEM USING FORWARD AND BACKWARD, 1(2), 61-67.

Sri Maharsi. (2000). the influence of the Development of Information Technology on the Field of Management Accounting. Jurnal Akuntansi Dan Keuangan, 2(2), 127-137. https://doi.org/10.9744/jak.2.2.pp. 127-137

Susanto, G. (2011). Medical Record Information System at Pacitan Regional General Hospital (RSUD) Based on Web Base, 3(4), 18-24.

Wardan, A. K. (2014). Relationship between family support and control of blood sugar levels with symptoms of microvascular complications. Periodic Epidemiology. Berkala Epidemiologi, 2(1), 1-12. 